\title{
Boundary conditions for the problem of moisture transport in concrete
}

\author{
Zaven Ter-Martirosyan, and Viktor Bakhmisov ${ }^{*}$ \\ Moscow State University of Civil Engineering, Yaroslavskoe shosse, 26, Moscow, 129337, Russia
}

\begin{abstract}
When calculating of the moisture transport in concrete of such geotechnical structures as a pile or diaphragm wall, contact with soil is forming the special boundary conditions. If the soil is in the full saturated state, then the Darcy's law should be used to solve the problem, the boundary condition for which is the water pressure. Otherwise, the BažantNajjar model is used, for which the boundary condition is the relative humidity of soil environment at a certain temperature. The soil environment temperature is unique characteristic for each construction area. For Moscow region, the weighted arithmetic mean temperature to the depth of $60 \mathrm{~m}$ is $7.3^{\circ} \mathrm{C}$. It is proposed to calculate the relative humidity of the soil environment according to the Kelvin capillary condensation equation, in which the suction is calculated using the Mualem-van Genuchten hydraulic model from the degree of saturation. Two wellknown sets of hydraulic parameters of the Mualem-van Genuchten model, compiled on the HYPRES and the HYDRUS-1D database from the European soil map texture classes and the USDA textural soil classification respectively, were compared with the measurement results for soil samples classified according to Russian the GOST 25100. The experimental data showed a good approximation to the calculation with a set of parameters obtained on the basis of the HYPRES database. At the same time, the solution with the HYDRUS-1D parameter set showed a poor correlation.
\end{abstract}

\section{Introduction}

Electron scanning microscope photographs with $22 \mathrm{x}$ and $11000 \mathrm{x}$ magnification [1] and numerous experimental studies show that concrete is a capillary-porous body and the moisture transport in it obeys the corresponding mechanisms. Experimental data from Baroghel-Bouny [2] show the presence of two types of isothermal moisture transfer curves - adsorption and desorption, which have the property of hysteresis. From a practical point of view, the desorption curve is the generally important, since most concrete structures are typically the drying over time $[3,4]$.

A large number of models have now been developed for calculating the moisture transport in concreate structures over time. They use different mechanisms of moisture transport, but they are always based on a gradient of some physical quantity.

Lykov [5] и Pihlajavaara [6] use as such the evaporable water content $w_{e}$ - the mass of water fraction referred to the volume of concrete, which is subject to evaporation. In turn, Krischer [7] in addition to $w_{e}$ took into account the partial vapor pressure in capillary pores

*Corresponding author: bahmisov7@live.com 
$p_{v}$. Aleksandrovsky [3] uses $U$ - gravimetric water content of concrete, which includes water in liquid and gaseous states. Pedersen [8], Nicolas [9], Künzel [1], Hagentoft et al. [10] took into account the partial vapor pressure in capillary pores $p_{v}$ and the liquid water pressure in the capillaries $p_{c}$. Moonen [11] used the gradient of the already known $p_{v}$, and introduced two additional ones - the pore gas pressure $p_{g}$ and the capillary water pressure $p_{l}$. Coussy [12] also used three parameters, but instead of the $p_{v}$ gradient he used its relative $p_{v} / p_{g}$ value. In the model of Gawin, Majorana and Schrefler [13] all the indicated gradients are taken into account $-p_{g}, p_{v} / p_{g}, p_{c}$ and $p_{l}$. Unlike the listed authors, Richards [14] uses Darcy's law and the corresponding concept of the total head $H_{t}$. Bažant and Najjar [15] created a model for conditions of incomplete water saturation, in which moisture to transport under the gradient of pore air relative humidity $h$.

According to [4], the saturated and unsaturated cases of moisture transport in concrete should be considered separately. Confirming this, the fib Model Code [16] recommends using Darcy's law for saturated state, and Bažant-Najjar diffusion model for isothermal unsaturated state. The boundary conditions for the use of these models correspond to the soil environment such geotechnical structures as piles, diaphragm walls, etc., therefore, below we will consider only them.

The boundary conditions for the model of moisture transport in saturated concrete according to Darcy's law will be water pressure at the contact with structure, and environmental relative humidity for unsaturated concrete under to the Bažant-Najjar model. Since soil is the environment for such structures as piles or diaphragm walls, it is necessary to take into account the relative humidity of soil environment [17]. Then the boundary conditions at soil contact with the geotechnical structures can be characterized by such parameters as temperature, the pore pressure and the relative humidity of the environment. In this work, we tried to formulate approach for the boundary conditions determination.

\section{Methods}

\subsection{The pore water pressure of soil environment}

The groundwater pressure is calculated common on geotechnical site survey data: at the steady-state water levels in boreholes, CPTU tests or data of specially installed sensors. If distribution of moisture in concrete is calculated according to the Darcy's law and the groundwater pressure acts on the one hand, then such the pressure will be the boundary condition on the side of the soil environment. If a pit is on the opposite side at the same time, then the Darcy's law boundary condition should be taken equal to the atmospheric [4].

\subsection{The underground temperature}

The temperature on piles boundary is determined only by soil environment. Diaphragm walls is influenced by the atmosphere temperature and by the absorbed heat flux of solar radiation from the pit side. If the diaphragm walls play a foundation role, then the temperature will also be influenced necessary by the underground room heat.

For simplicity, we propose to ignore fluctuations in atmosphere temperature and operate with the average yearly temperature. If solar insolation is significant, it is also possible to take into account the influence of the absorbed solar heat flow. One should use the hydrometeorological site survey data or use reference data in determining these parameters. The depth soil temperature distribution is unique for a certain area, but within one site it can be considered constant. Therefore, as an example, only Moscow region is considered, which is most relevant for the authors.

Typical the soils environment temperature distribution in the indicated area were studied, for example, in the paper of Kashpiryuk and Pyatkin [18]. Where monthly measurements of 
the depth soil temperature distribution until $60 \mathrm{~m}$ were carried out during 2012. In Korneva and Lokoshchenko paper [19] are presented data of average yearly soil temperature observation for Moscow region to a depth of $3.2 \mathrm{~m}$ from 1965 to 2013. The results of combine these two works made it possible to more reliably determined the average yearly underground environment temperature distribution from the surface to a depth of $60 \mathrm{~m}$.

\subsection{The underground relative humidity}

It is proposed to ignore relative humidity fluctuations, as well as in atmospheric temperature, considering only the average yearly values, which can also be obtained from the hydrometeorological site survey data or use reference data. In addition, it should be noted, that the effect of daily relative humidity fluctuations is not significant for massive concrete structures [4], such as the diaphragm walls.

In the capillary condensation process in the soil pore space by diameter of $10^{-3}$ до $10^{3} \mu \mathrm{m}$ accumulates the capillary water and is held by surface tension forces at the water-gas-solid surface interface. The capillaries in the diameter narrowing places are blocked by layers of capillary water and the vapor are loses the free movement possibility, when the degree of saturation of the soil is more than 50-60\% [20]. However, the process of moisture transport is not stop - under the relative humidity gradient influence, water to be evaporate from the concrete and condense in the soil capillaries, increasing its degree saturation until equilibrium is reached.

The soil environment relative humidity $R H$ can be determined by the following equation of Kelvin capillary condensation [21-23]

$$
R H=\frac{p}{p_{s}}=\exp \left(-\frac{\Psi_{w} M_{w}}{R T}\right)=\exp \left(-\frac{p_{w} M_{w}}{\rho_{w} R T}\right)=\exp \left(-\frac{0.01 h g M_{w}}{R T}\right)
$$

where $p$ - the partial pressure of water vapor, $\mathrm{Pa} ; p_{s}$ the equilibrium vapor pressure of water over a flat surface of pure water, $\mathrm{Pa} ; R$ - the gas constant; $T$ - the temperature of soil, $\mathrm{K}$; $M_{w}$ - the molar mass of water vapor, равный 0.018 кг/моль; $\Psi_{w}-$ water potential, $\mathrm{J} / \mathrm{kg} ; \rho_{w}$ - the water density; $p_{w}$ - the suction pore water pressure $\left(p_{w}>0\right), \mathrm{Pa} ; h$ - the pressure head, $\mathrm{cm} ; g$ - gravitational acceleration, $\mathrm{m} / \mathrm{s}^{2}$.

As can be seen from equation (1), only the temperature $T$ and the water potential $\Psi_{w}$ (or the suction pore water pressure $p_{w}$ or the pore water pressure $h$ ).

In many experiments to determine the water retention curves, it was found that the matrix pressure $\Psi_{m}$ is specific for different soils, since it characterizes the structure of their pore space and mineralogical composition [25]. These qualities led to the development of methods for determining the matrix pressure based on the Jurin's law, which allows calculating the height of a liquid column depending on the capillary diameters, its characterized by the grain size distribution [2626]. The accumulation of experimental data has led to emergence of functional relationships between soil moisture / water saturation and the matrix potential, for example, Brooks and Corney [27], van Genuchten [28] and Kosugi [29]. The use of such models allows us to calculate the matrix potential values through the water content using both analytical and numerical methods [30]. Substituting it into equation (1), it is possible to obtain the soil environment relative humidity distribution over the entire the soil-concrete boundary.

At present, most widespread is the Mualem-van Genuchten model [28], according to which the current sample volumetric moisture content can be calculated by the pressure head using the following formula 


$$
\theta=\theta_{r}+\frac{\theta_{s}-\theta_{r}}{\left[1+(\alpha h)^{n}\right]^{m}}
$$

where $\theta$ - the volumetric water content, $\mathrm{cm}^{3} / \mathrm{cm}^{3} ; \theta_{r}$ - the residual volumetric water content, $\mathrm{cm}^{3} / \mathrm{cm}^{3} ; \theta_{s}$ - the saturated volumetric water content, $\mathrm{cm}^{3} / \mathrm{cm}^{3} ; h$ - the pressure head, $\mathrm{cm} ; \alpha$ - the fitting parameter approximates air-entry height of the capillary fringe, $\mathrm{cm}^{-}$ ${ }^{1} ; n$ - the fitting parameter is connected to the pore size distribution; $m$ - the fitting parameter characterizing to the symmetry of the water retention curves.

Significant work on defining the Mualem-van Genuchten model parameters for soils classified by grain size distribution according to the European soil map texture classes (see Figure 4) was presented in the article by Wösten et al. [31]. In this work, data on 5521 soil samples were analyzed, regression equations were obtained, and the calculation results were tabulated.

Table 1. The Mualem-van Genuchten parameters for the fits on the geometric mean curves of soils, these classified by European soil map texture classes (reprinted from Wösten et al.

[31])

\begin{tabular}{|c|c|c|c|c|c|}
\hline & $\theta_{r}$, д.е. & $\theta_{s}$, Д.е. & $\alpha, \mathrm{cm}^{-1}$ & $n$ & $m$ \\
\hline \multicolumn{6}{|l|}{ Topsoils } \\
\hline Coarse & 0.025 & 0.403 & 0.0383 & 1.3774 & 0.2740 \\
\hline Medium & 0.010 & 0.439 & 0.0314 & 1.1804 & 0.1528 \\
\hline Mediumfine & 0.010 & 0.430 & 0.0083 & 1.2539 & 0.2025 \\
\hline Fine & 0.010 & 0.520 & 0.0367 & 1.1012 & 0.0919 \\
\hline Very Fine & 0.010 & 0.614 & 0.0265 & 1.1033 & 0.0936 \\
\hline \multicolumn{6}{|l|}{ Subsoils } \\
\hline Coarse & 0.025 & 0.366 & 0.0430 & 1.5206 & 0.3424 \\
\hline Medium & 0.010 & 0.392 & 0.0249 & 1.1689 & 0.1445 \\
\hline Mediumfine & 0.010 & 0.412 & 0.0082 & 1.2179 & 0.1789 \\
\hline Fine & 0.010 & 0.481 & 0.0198 & 1.0861 & 0.0793 \\
\hline Very Fine & 0.010 & 0.538 & 0.0168 & 1.0730 & 0.0680 \\
\hline Organic $^{a}$ & 0.010 & 0.766 & 0.0130 & 1.2039 & 0.1694 \\
\hline
\end{tabular}

${ }^{\mathrm{a}} \mathrm{Within}$ the organic soils no distinction is made in topsoils and subsoils

The HYDRUS-1D catalog (Carsel and Parrish [32]) contains the data of the Mualem-van Genuchten model hydraulic parameters for 12 USDA texture classes (see Figure 4). The average values of these parameters presented in Table 2 were obtained from Rahmati et al. [33].

Table 2. Average soil hydraulic parameters for the Mualem-van Genuchten model for 12 USDA textural classes by HYDRUS-1D database (reprinted from Rahmati et al. [33])

\begin{tabular}{|c|c|c|c|c|c|}
\hline Textural class & $\boldsymbol{\theta}_{\boldsymbol{r}}$ o.e. & $\boldsymbol{\theta}_{\boldsymbol{s}}$, $\boldsymbol{\text { .e}} \boldsymbol{.}$ & $\boldsymbol{\alpha , \boldsymbol { c m } ^ { - \boldsymbol { 1 } }}$ & $\boldsymbol{n}$ & $\boldsymbol{m}$ \\
\hline Clay & 0.068 & 0.38 & 1.09 & 0.083 & 0.271 \\
\hline Clay loam & 0.095 & 0.41 & 1.31 & 0.237 & 0.15 \\
\hline Loam & 0.078 & 0.43 & 1.56 & 0.359 & 0.088 \\
\hline Loamy sand & 0.057 & 0.41 & 2.28 & 0.561 & 0.057 \\
\hline
\end{tabular}




\begin{tabular}{|c|c|c|c|c|c|}
\hline Sand & 0.045 & 0.43 & 2.68 & 0.627 & 0.045 \\
\hline Sandy clay & 0.1 & 0.38 & 1.23 & 0.187 & 0.17 \\
\hline Sandy clay loam & 0.1 & 0.39 & 1.48 & 0.324 & 0.111 \\
\hline Sandy loam & 0.065 & 0.41 & 1.89 & 0.471 & 0.066 \\
\hline Silt & 0.034 & 0.46 & 1.37 & 0.27 & 0.09 \\
\hline Silt loam & 0.067 & 0.45 & 1.41 & 0.291 & 0.104 \\
\hline Silt clay & 0.07 & 0.36 & 1.09 & 0.083 & 0.266 \\
\hline Silty clay loam & 0.089 & 0.43 & 1.23 & 0.187 & 0.197 \\
\hline
\end{tabular}

Korolev and Bludushkina [34] published results of determining the suction pressure at variable the sand samples water content with various the grain size distribution. Given in the article the results were processed by recalculating the values from the curves according to the formula (1) from the dependence type "suction pressure - water content" to the type "relative humidity - degree of saturation".

\section{Results}

As the review result of existing methods for calculating the moisture transport in concrete, it was found that most suitable for the geotechnical structures are the Richards method [14], which uses the Darcy's law for the saturated soil environment, and the Bažant and Najjar model [15] for the unsaturated conditions.

\subsection{The underground temperature}

The temperature range $T \in\left[0^{\circ} \mathrm{C} ;+20^{\circ} \mathrm{C}\right]$ was accepted to determine the sensitivity of equation (1) to the temperature changes, for which the function $R H=f\left(\Psi_{w}\right)$ curves were plotted in Figure 1. It can be seen that the maximum change in $R H$ does not exceed $2.5 \%$ at $\Delta T=20^{\circ} \mathrm{C}$. This can be characterized as a low-sensitivity of the considered function to temperature changes.

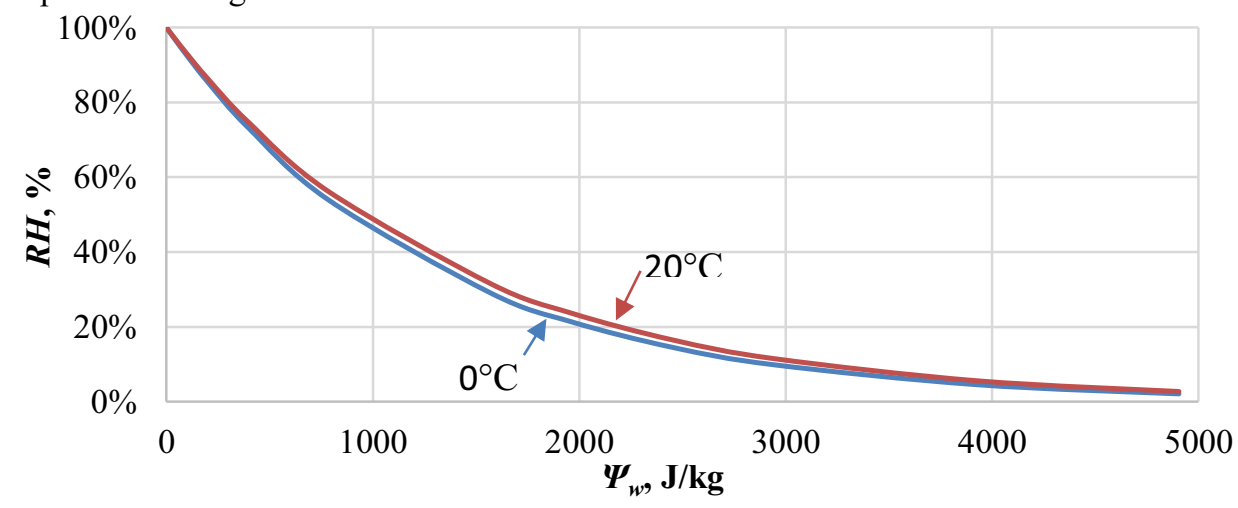

Fig. 1. The function $R H=f\left(\Psi_{w}\right)$ dependence from the temperature change

During data analyses [18, 19], it was determined that the soil temperature in Moscow region, to a depth of $35 \mathrm{~m}$, it predominantly has a value of $7.2^{\circ} \mathrm{C}$, by $60 \mathrm{~m}$ it increases to $7.7^{\circ} \mathrm{C}$. The weighted arithmetic mean temperature for the considered depths is $7.3^{\circ} \mathrm{C}$. The curve of the average yearly temperature by depth is shown in Figure 2. 


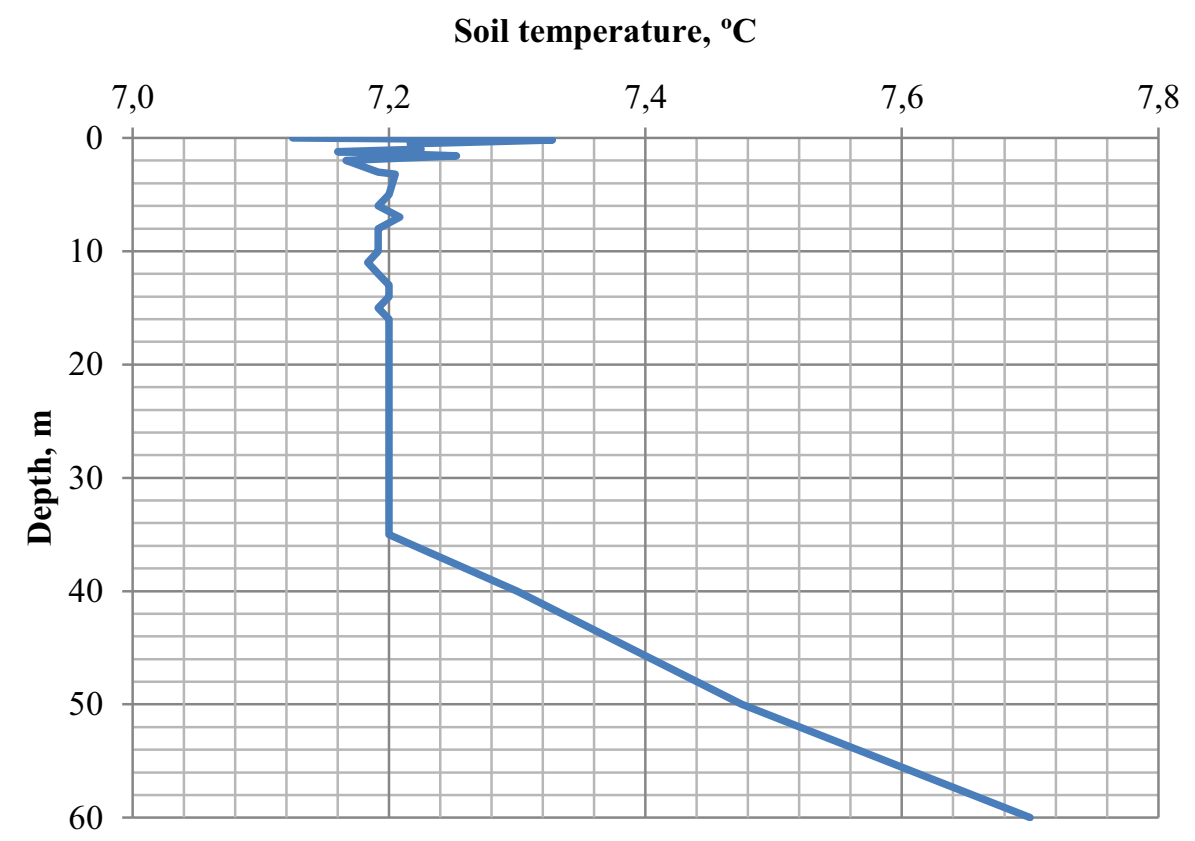

Fig. 2. The average yearly underground environment temperature for Moscow region

\subsection{The underground relative humidity}

It has been proven that the water content in soil volume is function on the water potential $\Psi_{w}$ [24]. This dependence is called the water retention curves (WRC or SWRC), which is usually presented in the form dependence between the volumetric water content on the matric suction $\Psi_{m}[25]$.

Since the soil environment relative humidity $R H$ depends on the matrix suction according to equation (1), it was calculating to use the most common hydraulic model Mualem-van Genuchten [28] to determine it. Solving equation (2) for $h$ and substituting it in formula (1), we obtain the dependence of the soil environment relative humidity on the volumetric water content

$$
R H=\exp \left(-\frac{0.01 g M_{w}}{\alpha R T}\left[\left(\frac{\theta_{s}-\theta_{r}}{\theta-\theta_{r}}\right)^{\frac{1}{m}}-1\right]^{\frac{1}{n}}\right)
$$

Let us substitute the well-known equation of soil mechanics for the dependence of the volumetric soil moisture $\theta$ on the degree of saturation $S$ and the void ratio $e(4)$ into formula (3) to obtain a function of the form $R H=f(S, e)$ (5).

$$
\theta=\frac{S e}{1+e}
$$




$$
R H=\exp \left(-\frac{0.01 g M_{w}}{\alpha R T}\left[\left(\frac{\theta_{s}-\theta_{r}}{\frac{S e}{1+e}-\theta_{r}}\right)^{\frac{1}{m}}-1\right]^{\frac{1}{n}}\right)
$$

The results of data analysis [34] for 8 sandy soil samples are shown in Figure 3. At the same time, the samples coordinates were plotted on the combined triangular scheme of the European soil map texture classes and the USDA textural soil classification in Figure 4. As can be seen from it, samples of sandy soils classified by the grain size distribution in accordance with Russian the GOST 25100 as silty (red), fine (blue) and medium (green) sands are located in the COARSE and sand / loamy sand areas, respectively.

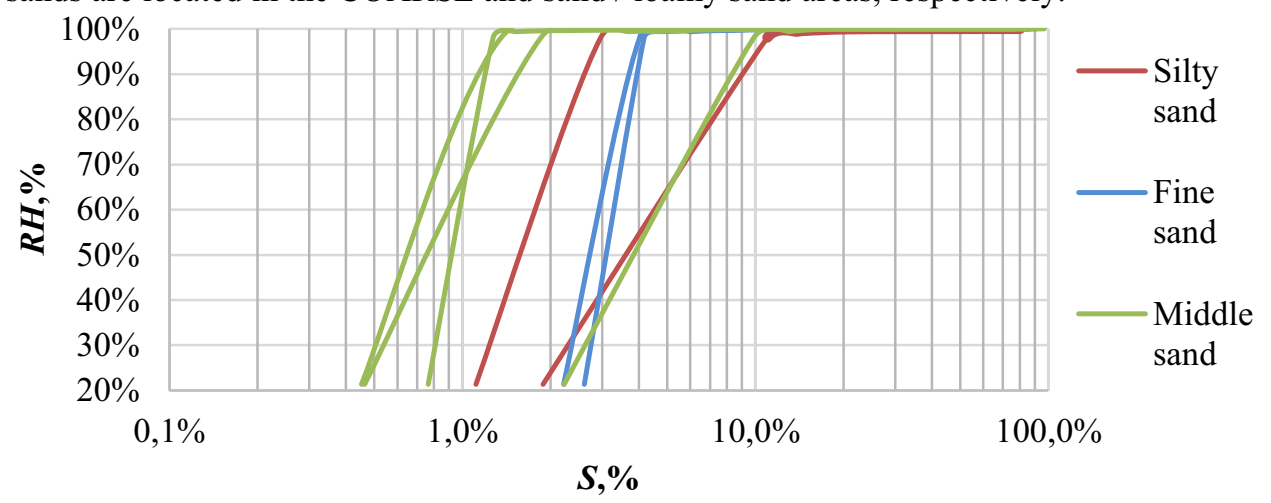

Fig. 3. Dependence of the relative humidity of sands classified in the GOST 25100 from the degree of saturation

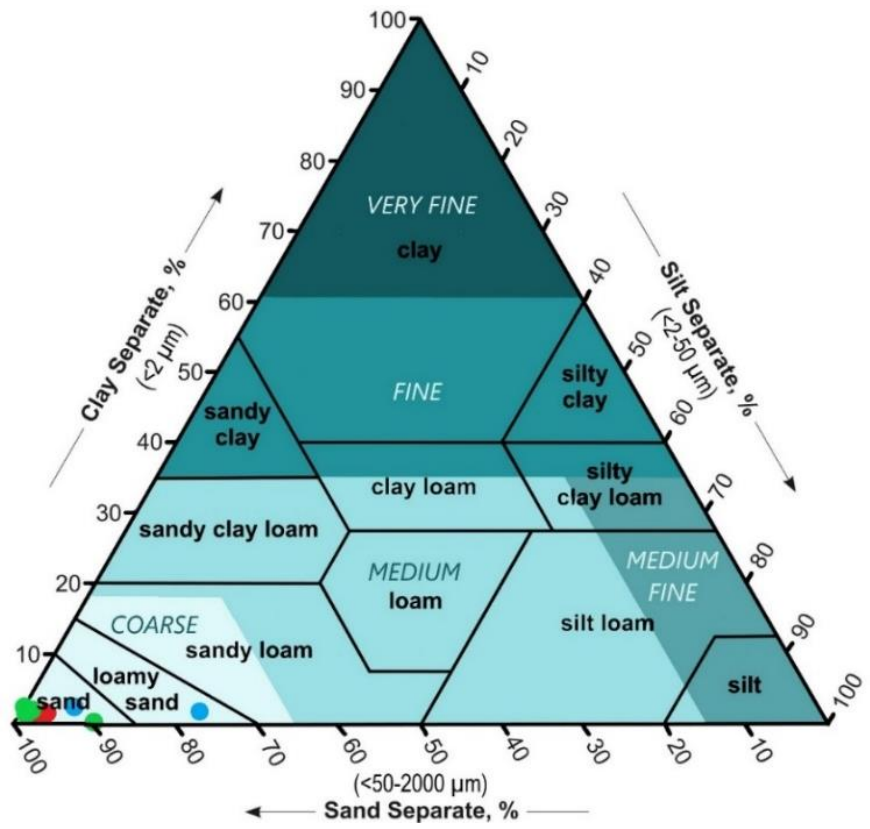

Fig. 4. Combination result of the European soil map texture classes (areas are marked with colorization) and the USDA textural soil classification (areas are marked with bold contour lines) combined, with coordinates test the samples [34] 
Using formula (5) and the Mualem-van Genuchten model hydraulic parameters given in Tables 1 and 2, graphs the relative humidity from the degree of saturation were plotted with the mean values the void ratio for the samples $e=0.66$ and temperature $T=7.3^{\circ} \mathrm{C}$. The calculated curves and the average curve for 8 samples of experimental data [34] are plotted in Figure 5 for comparison.

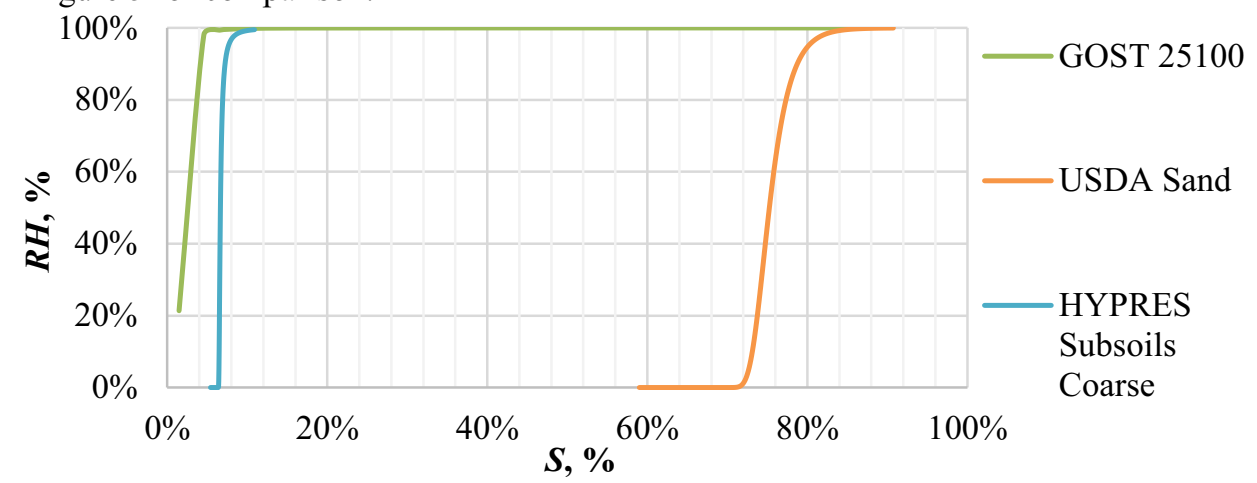

Fig. 5. Comparison of the arithmetic mean results of direct measurements for the samples [34] with solution by the HYPRES parameters [31] and HYDRUS-1D [32, 33] database

As can be seen from Figure 5, for sands classified by the grain size distribution according to the GOST 25100 as silty, fine and medium (red, green and blue points in Figure 8 respectively), the measured data were quite close to the results of calculations using the Mualem-van Genuchten model with the HYPRES database hydraulic parameters set [31]. At the same time, the solution obtained with the HYDRUS-1D parameters set $[32,33]$, showed a poor match with the experimental data.

\section{Discussion}

The following method is proposed for determining the boundary conditions for calculating the moisture transport in concrete of geotechnical structures.

When the structure contacted with the saturated soil, one should use the Richards method [14] with the corresponding the Darcy's law boundary conditions - the groundwater pressure, which should be calculated from the geotechnical site survey data, such as at the steady-state water levels in boreholes, CPTU tests or data of specially installed sensors.

When the structure contacted with the saturated soil, the moisture transport in concrete should be calculated according to the Bažant-Najjar model [15], and the soil environment relative humidity for its the boundary condition should be calculated using equation (5). Then, for soils classified according to the GOST 25100, one should use the Mualem-van Genuchten model [28] hydraulic parameters, established from the HYPRES database [31], having previously determined the coordinates of the soil on the European soil map texture classes by the grain size distribution of a sample. In this case, the soil environment temperature should be determined by direct measurements from the borehole or using reference data. Also, the building underground space influence on the soil temperature in most engineering cases can be neglected due to the weak sensitivity of the equation.

\section{References}

1. H.M. Künzel. Simultaneous heat and moisture transport in building components, Tech. Rep., Fraunhofer Inst. of Build. Phys. (IRB Verlag, Stuttgart,1995)

2. V. Baroghel-Bouny, Cem. and Conc. Res., 37, 414-437 (2007) 
3. S.V. Aleksandrovskij, Raschet betonnyh i zhelezobetonnyh konstrukcij na izmenenija temperatury i vlazhnosti s uchetom polzuchesti betona (Moscow, Res. Inst. of Conc. and Rein. Conc., 2004)

4. Z. Bažant, M. Jirásek, Creep and Hygrothermal Effects in Concrete Structures (Dordrecht, Imprint, 2018)

5. A.V. Lykov, Javlenija perenosa v kapilljarno-poristych telach (Moscow, Gos. Izd. teh.-teor. lit., 1954)

6. S.E. Pihlajavaara, Bul. RILEM, 27, 61-63 (1965)

7. O. Krischer, VDI - Forschungsheft, 415, 1-22 (1942)

8. C.R. Pedersen, Ph.D. thesis (Technical University of Denmark, 1990)

9. P. Nicolas, Ph.D. thesis (Université Paris VI, 1992)

10. C. Hagentoft, A. Kalagasidis, B. Adl-Zarrabi, S. Roels, J. Carmeliet, H. Hens et al., J. Of Therm. Env. And Build. Scien., 27, 327-352 (2004)

11. P. Moonen, Ph.D. thesis (Delft University of Technology, 2009)

12. O. Coussy, Mechanics and physics of porous solids (Chichester, Wiley, 2010)

13. D. Gawin, C.E. Majorana, B. Schrefler, Mech. of Coh.-Frict. Mat., 4, 37-74 (1999)

14. L.A. Richards, J. of Ap. Phys., 1, 318-333 (1931)

15. Z.P. Bažant, L.J. Najjar, Cem. and Conc. Res., 1, 461-473 (1971)

16. fib Model Code For Concrete Structures 2010 (Berlin, Ernst \& Sohn, 2013)

17. Z.G. Ter-Martirosyan, V.V. Bakhmisov, Vestnik MGSU, 15, 1285-1296 (2020)

18. P.I. Kashperyuk, D.S. Pyatkin, Ing. Geol., 5, 52-58 (2017)

19. I.A. Korneva, M.A. Lokoshchenko, Rus. Met. and Hyd., 40, 25-33 (2015)

20. V.T. Trofimov, V.A. Korolev, E.A. Voznesenskiy, G.A. Golodkovskaya, Yu.K. Vasil'chuk, R.S. Ziangirov, Soil science (Moscow, MSU Publ., 2005)

21. G. Sposito, Termodinamika Pochvennyh (Leningrad, Hydrometeoizdat, 1984)

22. J. Bear, Modeling phenomena of flow and transport in porous media (Cham, Springer, 2018)

23. A. Amer, Water Vapor Adsorption and Soil Wetting, Wetting and Wettability (2015)

24. V.A. Korolev, R.I. Zlochevskaya, Prob. Inzh. Geol.: Sb.nauch.tr., Moscow: Nauka, 35$56(1991)$

25. E.V. Shein, Kurs fiziki pochv (Moscow, MSU Publ., 2005)

26. E.V. Shein, L.O. Karpachevsky, Teorii i metody fiziki pochv (Moscow, Grif and K. Publ, 2007)

27. R.H. Brooks, A.T. Corey, Trans. ASAE, Trans. of the ASAE., 7, 26-28 (1964)

28. M.T. van Genuchten, Soil Sci. Soc. Am. J., 44, 892-898 (1980)

29. K. Kosugi, Water Resour. Res., 32, 2697-2703 (1996)

30. V. Chiorean, IOP Conf. Ser.: Mater. Sci. Eng., 245, 032074 (2017)

31. J. Wösten, A. Lilly, A. Nemes, C. Le Bas, Geoderma, 90, 169-185 (1999)

32. R. Carsel, R. Parrish, Wat. Resour. Res., 24, 755-769 (1988)

33. M. Rahmati, J. Vanderborght, J. Šimůnek, et al., Vadose Zone J., 19, e20068 (2020)

34. V.A. Korolev, L.B. Bludushkina, Ing. Geol., 4, 22-32 (2015)

All tests were carried out using research equipment of The Head Regional Shared Research Facilities of the Moscow State University of Civil Engineering. 